\title{
Desain Infrastruktur dan Pemanfaatan Cloud Computing di Perusahaan Berskala Kecil Menengah sebagai Pendukung Kegiatan Operasional
}

\author{
David Sundoro \\ Program Studi Sistem Informasi \\ Universitas Matana \\ david.sundoro@gmail.com
}

\begin{abstract}
Abstrak - Pemanfaatan teknologi informasi dalam berbagai bidang industri. Namun perkembangan teknologi yang juga begitu cepat, membuat banyaknya variasi pilihan teknologi yang bisa dipergunakan sebagai solusi. Penelitian kali ini, menyajikan pemilihan teknologi yang bisa menjadi alternatif bagi penggunaan teknologi sebelumnya yang sudah diimplementasikan, tanpa mengorbankan kebutuhan dari badan usaha yang mempergunakan teknologi informasi tersebut. Sehingga di dalam menerapkan suatu teknologi, perlu memperhatikan kebutuhan yang sebenarnya dari bisnis yang dijalankan.
\end{abstract}

Kata Kunci - Cloud Computing, Desain Infrastruktur

\section{PENDAHULUAN}

Pada kelompok usaha milik perseorangan yang masih tergolong kecil atau sedang (Kelompok UMKM), kebutuhan akan teknologi informasi tidak atau belum sebesar perusahaan yang memiliki skala besar atau enterprise. Namun tidak pelak, teknologi informasi tetap dibutuhkan dalam operasional perusahaan, dalam usahanya mencapai keunggulan bersaing. Beberapa usaha milik perseorangan atau UMKM, kebutuhan berbagi-pakai data yang bisa dilakukan dari beberapa tempat yang berbeda, juga tidak bisa dihindari. Seperti penggunaan data antara store dan warehouse, yang tidak berada dalam satu area yang sama. Selama ini solusi yang dipilih adalah dengan memanfaatkan teknologi informasi berupa koneksi nirkabel (wireless) peerto-peer (P2P).

Penelitian ini bertujuan untuk mencari solusi alternatif dari layanan teknologi informasi yang dipergunakan agar tetap bisa memenuhi kebutuhan berbagi-pakai data dalam bisnis, tanpa harus mempergunakan teknologi yang robust.

\section{Teknologi Nirkabel (Wireless) P2P}

\section{TINJAUAN LITERATUR}

Teknologi nirkabel adalah model desentralisasi komunikasi dimana setiap peserta memiliki kemampuan yang sama dan diperbolehkan untuk melakukan inisiasi dalam berkomunikasi. Dalam model jaringan P2P, setiap titik (node) dapat berfungsi sebagai client maupun server (Motta, 2010).
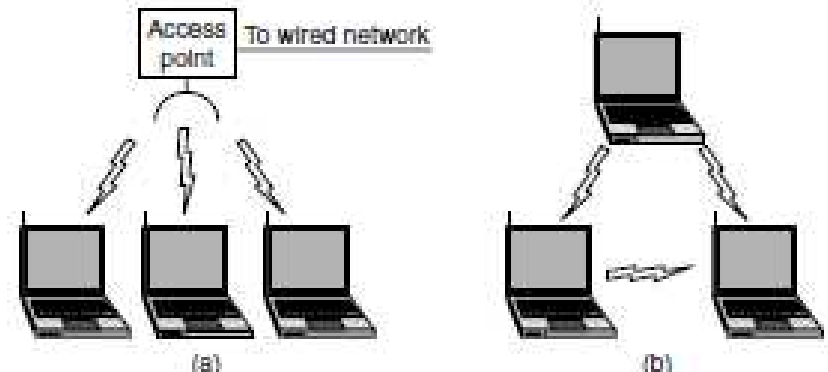

(b)

Gambar 1. Konsep dasar komunikasi nirkabel (Tanenbaum, 2010)

\section{Cloud Computing dan Cloud Storage}

Dalam beberapa tahun terakhir, paradigma cloud computing telah membuktikan pergeseran yang luar biasa terhadap adopsi teknologi ini, bahkan sudah menjadi tren dalam ranah teknologi informasi bahwa cloud computing bisa menekan biaya secara signifikan dan bisa memberikan potensi bisnis yang besar bagi pengguna dan penyedianya (Wang et al, 2008).

Manfaat dari penggunaan cloud computing (Bhadauria, 2012) antara lain adalah sebagai berikut :

a) Mengurangi biaya pembelian perangkat keras dan pemeliharaannya

b) Memperoleh akses dari mana saja, selama terjangkau oleh akses internet

c) Memiliki tingkat fleksibilitas dan proses otomatis yang tinggi, sehingga pengguna tidak perlu merasa kuatir dengan masalah-masalah yang timbul seperti proses upgrade perangkat lunak atau platform. 


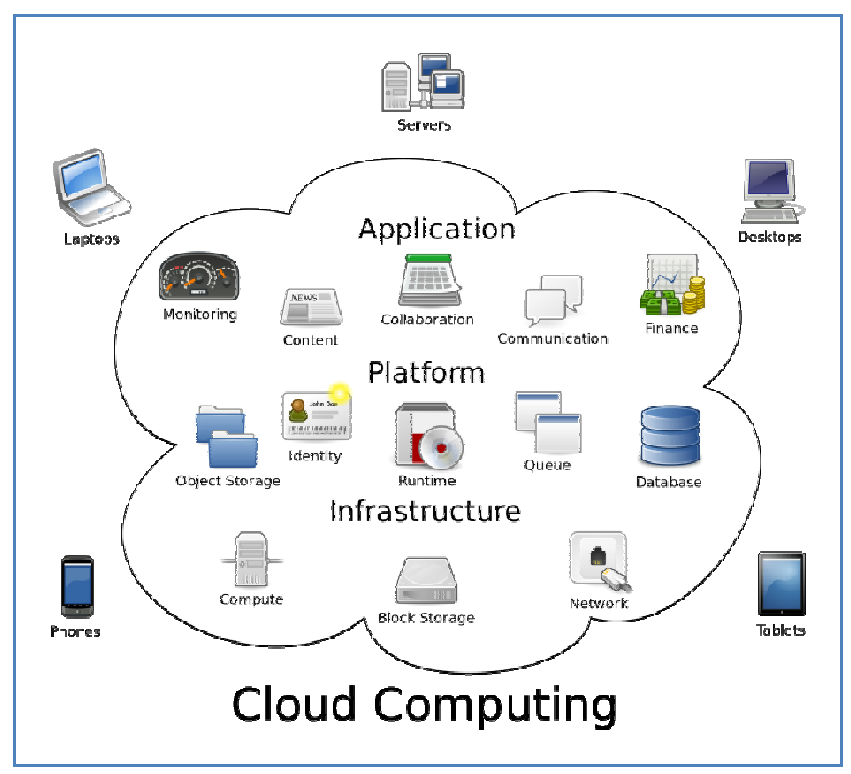

Gambar 2. Konsep umum Cloud Computing (http://techonomy.com/wp-content/uploads/2012/08/cloudcomputing-diagram.png)

\section{METODOLOGI PENELITIAN}

Penelitian dilakukan terhadap salah satu badan usaha milik perseorangan yang berukuran kecil-menengah, yang memang sedang mencari solusi alternatif tentang kebutuhan berbagi-pakai data dari 2 (dua) tempat yang berbeda, yang tidak memiliki syarat real-time. Bnadan usaha tersebut mempergunakan koneksi peer-to-peer dengan memanfaatkan teknologi wireless, antara front store dan warehouse.

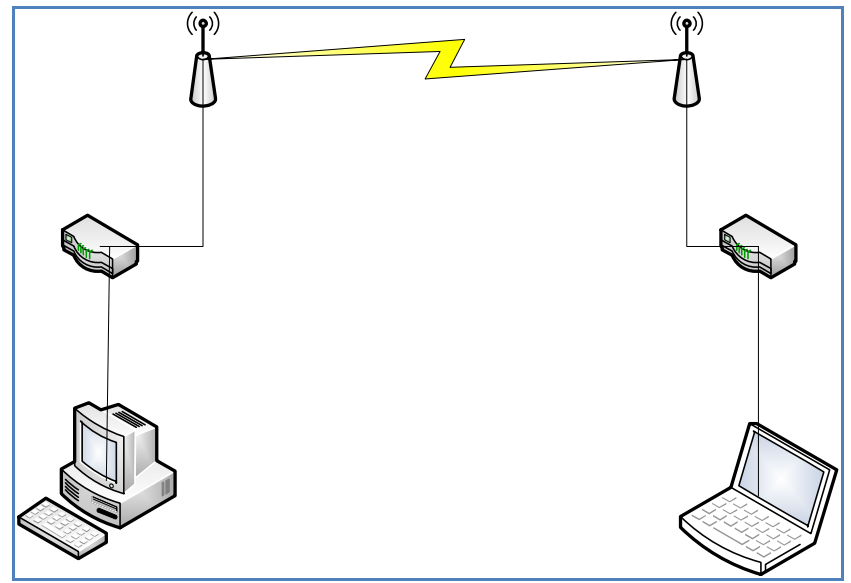

Gambar 3. Topologi yang dipergunakan dalam menghubungkan front store dan warehouse

Dari Gambar 3, dapat dilihat bahwa kebutuhan dalam komunikasi antar node, membutuhkan perangkat yang relatif cukup bagus seperti :

1. Router sebanyak 2 unit

2. Access point sebanyak 2 unit
3. Outdoor antenna sebanyak 2 unit

Kebutuhan perangkat diatas masih belum termasuk pada perangkat komputer dan storage beserta pemeliharaaanya yang harus disediakan.

Dalam wawancara dengan pengelola badan usaha, diperoleh beberapa hal sebagai berikut :

1. Komunikasi data tersebut tidak memerlukan faktor realtime dalam pemenuhan kebutuhannya, dan yang dibutuhkan hanya keterbaruan dari data.

2. Dari sisi aplikasi, badan usaha ini masih mempergunakan aplikasi berbasis desktop, untuk memenuhi kebutuhannya. Dan dinilai masih belum membutuhkan aplikasi berbasis client-server.

3. Kebutuhan yang lain adalah, data tersebut juga idealnya bisa diakses dari mana saja, agar bisa pantau perkembangannya sewaktu-waktu, oleh pengelola badan usaha.

Berdasarkan hasil wawancara tersebut, didesain satu solusi yang memanfaatkan cloud storage sebagai alternatif yang dapat dipergunakan sebagai solusi bagi badan usaha ini. Ada pun desain koneksi cloud storage yang dibuat, dapat dilihat pada Gambar 4.

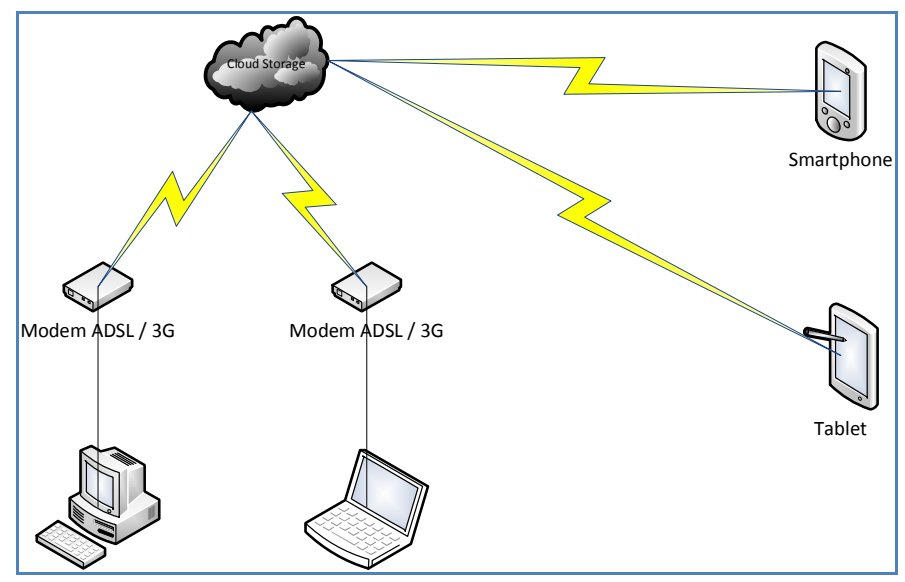

Gambar 4. Topologi yang dipergunakan dengan memanfaatkan cloud storage

Berdasarkan Gambar 4, terlihat bahwa pemenuhan kebutuhan untuk penggunaan data bersama-sama menjadi lebih sederhana dengan memanfaatkan layanan cloud storage. Adapun perangkat yang dipergunakan (dikatakan lebih sederhana) hanya 2 unit modem ADSL atau 3G agar pengguna bisa terhubung dengan cloud storage.

\section{KESIMPULAN DAN IMPLIKASI MANAJERIAL}

Dalam memanfaatkan teknologi informasi, layanan cloud storage dan cloud computing merupakan salah satu alternatif yang bisa dipergunakan di dalam memenuhi kebutuhan usaha akan data dan informasi. Hal ini bisa mendorong perusahaan untuk tetap memperoleh keunggulan kompetitif dalam 
memberikan layanan atau membuat keputusan, tanpa harus melakukan implementasi teknologi yang robust dan mahal dalam menjalankan usahanya.

Bagi manajerial perusahaan, ini dapat dimanfaatkan agar meningkatkan daya saing. Terlebih jika dapat memenuhi kebutuhan data yang bersifat real-time, dengan memanfaatkan cloud computing, yang terdiri dari cloud storage dan cloud applications.

\section{PELUANG RISET DI MASA MENDATANG}

Dapat diteliti tentang analisa biaya manfaat dari cloud computing bagi perusahaan mikro, kecil dan menengah (UMKM) dan apa saja faktor yang mempengaruhi keberhasilan layanan cloud computing ini dalam usaha yang dijalankan.

Dari sisi bisnis, dapat dilihat juga seberapa besar pengaruh pemanfaatan teknologi cloud storage ini di dalam kinerja perusahaan.

\section{REFERENSI}

[1] Andrew Tanenbaum and David J Wetherall, 2010. Computer Networks $5^{\text {th }}$ Edition, Prentice Hall

[2] Rohit Bhadauria and Sugata Sanyal, 2012. Survey on Security Issues in Cloud Computing and Associated Mitigation Techniques.

[3] Lynda M. Applegate, Robert D Austin and Deborah L Soule, 2009. Corporate Information Strategy and Management $8^{\text {th }}$ Edition, Mc Graw-Hill

[4] Rossan Motta and Joseph Pasquale, 2010. Wireless P2P: Problem or Opportunity?

David Sundoro adalah seorang staf pengajar pada Program Studi Sistem Informasi di Universitas Matana, Tangerang. Bidang riset yang diminati adalah Manajemen Proyek Teknologi Informasi, Sistem Informasi Manajemen, Jaringan Komputer, dan Intelijen Bisnis, Saat ini tercatat sebagai mahasiswa Program Doktoral Bidang Manajemen Sistem Informasi di Universitas Bina Nusantara, Jakarta. 